\title{
The bidirectional interation between pancreatic cancer and diabetes
}

\author{
Junhui Li', Gang Cao ${ }^{1 *}$, Qingyong Ma², Han Liu², Wei Li and Liang Han²
}

\begin{abstract}
The bidirectional interation between pancreatic cancer (PanCa) and diabetes has been confirmed by epidemiological studies, which provide evidence-based medical support for further research into the mechanisms involved in the interaction. We reviewed the literature regarding the role of diabetes in the generation and progression of PanCa and the mechanism by which PanCa induces diabetes for its malignant progression. The effect of antidiabetic drugs on the occurrence and prognosis of PanCa was also reviewed. Diabetes may directly promote the progression of PanCa by pancreatic duct enlargement and hypertension, as well as by enabling an increased tumor volume. Hyperinsulinemia, insulin resistance, cytokines, hyperglycemia and genotype change are also important factors in the progression of PanCa with diabetes. Hyperglycemia may be the first clinical manifestation and is helpful in the early diagnosis of PanCa. Furthermore, antidiabetic drugs can have different effects on the occurrence and prognosis of PanCa. The bidirectional interation between PanCa and diabetes is involved in the occurrence, proliferation, invasion, metastasis and prognosis of PanCa with diabetes. The discovery of biomarkers for the early diagnosis of PanCa, as well as the novel usage of metformin for its antitumor effects and determining the potential mechanisms of these effects, may be the next direction for PanCa research and treatment.
\end{abstract}

Keywords: Review, Pancreatic cancer, Diabetes, Bidirectional interation

\section{Review} Introduction

Pancreatic cancer (PanCa) ranks fourth in the United States and eighth to ninth worldwide among cancerrelated deaths. From 1999 to 2008, the incidence rate of PanCa increased among men and women. During the same period, death rates increased for pancreatic cancer among both men and women. PanCa is more common in elderly persons aged 60 years and older, with fewer than $7 \%$ of patients presenting with localized, potentially curable tumors and approximately $53 \%$ of patients presenting with distant metastases. The overall five-year survival rate among patients with pancreatic cancer is $<6 \%[1,2]$.

The bilateral causality between PanCa and diabetes has been widely documented. Type 2 diabetes could be either a cause, and/or possibly a consequence of PanCa [3].

\footnotetext{
*Correspondence: ljh991049@yahoo.com.cn

'Department of General Surgery, Second Affiliated Hospital, School of Medicine, Xi'an Jiaotong University, 157 West 5th Road, Xi'an 710004, People's Republic of China

Full list of author information is available at the end of the article
}

Increased incidence of PanCa in diabetic patients

Epidemiological studies have confirmed a higher incidence of PanCa in diabetic patients. A meta-analysis of cohort studies reported that individuals in whom diabetes had only recently been diagnosed ( $<1$ year) had greater risk of malignancy in both males and females and that diabetes mellitus (DM) is both an early manifestation and an etiologic factor of pancreatic cancer [4]. Li et al. explored the association between diabetes and risk of PanCa in 2,192 cases and 5,113 controls in three large case-control studies using the method of multivariable analyses and found that diabetes was associated with a 1.8-fold risk of PanCa [5]. In a cohort study, Ogunleye et al. found the risk ratio to be significantly increased for pancreatic, liver and colon cancer [6]. Magruder et al. also reported that longstanding diabetes increases the risk of pancreatic cancer by $40 \%$ to $100 \%$. Recent-onset diabetes is associated with a 4- to 7 -fold increase in risk, such that $1 \%$ to $2 \%$ of patients with recent-onset diabetes will develop pancreatic cancer within three years [7]. Johnson et al. performed a population-based retrospective cohort study and found 
that within three months following diabetes onset, diabetics had a significantly increased risk of PanCa [8]. A population-based cohort study of 37,926 child-bearing Israeli women with a 28 - to 40 -year follow-up for diabetes and PanCa showed a 7 -fold increase in the relative risk for PanCa development in women with a history of gestational diabetes mellitus. Furthermore, glucose levels in the upper range of normal have been associated with an increased risk for the development of some cancers, including PanCa [9]. Several studies have confirmed type II diabetes as a risk factor for PanCa. But rare research about the relationship between dyslipidemia and PanCa is reported. Tseng presented a new viewpoint that dyslipidemia was a significant risk factor for PanCa with a random sample of 1 million subjects, which would be helpful for clarifying the mechanisms of metabolic syndrome on PanCa [10].

A regional disparity was also found in diabetesassociated PanCa. For example, Hispanic men and Asian individuals had a higher risk of diabetes-associated PanCa than did white and black individuals, although the differences were not statistically significant [5]. Ogawa et al. found that in Japan the prevalence of PanCa in a group of individuals diagnosed with recentonset diabetes (within three years) was $13.6 \%$, which was significantly greater compared with the group of individuals who were diagnosed with diabetes more than three years prior (2.0\%) [11]. Hong et al. reported a prevalence of PanCa among diabetic patients of $1.6 \%$ and a prevalence of diabetes in PanCa patients of $40.6 \%$ in Korea [12]. Chari et al. reported that approximately $1 \%$ of diabetics aged $\geq 50$ years will be diagnosed with pancreatic cancer within three years of first meeting the criteria for diabetes. Furthermore, in 2,122 individuals in the USA, 10 of $18(56 \%)$ were diagnosed $<6$ months after first meeting the criteria for diabetes [13]. An additional study in Americans analyzed a total of 1,172,496 case and control subjects and found that the frequency of pancreatic cancer in subjects with diabetes was $0.9 \%$ in comparison to subjects without diabetes (0.3\%) [14].

Stevens et al. conducted a systematic review of the risk of pancreatic cancer in people with type 1 and youngonset diabetes, and found an increased risk of pancreatic cancer in type 1 diabetics, based on 39 cases of pancreatic cancer in young-onset and type 1 diabetes [15].

\section{Increased incidence of diabetes in PanCa patients}

Tumor removal in PanCa patients improved glucose metabolism, which may suggest the presence of diabetogenic effect of PanCa [16]. Diabetes, especially new onset, is more frequent in PanCa patients and has been considered an early manifestation for asymptomatic PanCa. Approximately $80 \%$ of PanCa patients have glucose intolerance or frank diabetes [17]. In a populationbased case-control study of PanCa, participants with
PanCa were more likely to report a history of diabetes (13\%) and had a shorter duration of diabetes and a larger proportion of insulin users than the control groups [18]. Diabetes has a high (50\%) prevalence in PanCa and is frequently new onset ( $<36$ months before index) in subjects with PanCa compared with subjects without PanCa [19]. At the time of diagnosis, $80 \%$ of PanCa patients have either impaired glucose tolerance or diabetes [20]. The incidence of diabetes is $34.63 \%$ among PanCa patients in China, of which $74.56 \%$ experience diabetes onset within two years of cancer diagnosis [21]. Matsubayashi et al. found the patients with familial PanCa were more likely to have diabetes mellitus (32.5\%) than sporadic cases [22]. However, Bartsch et al. reported there were no statistical significant differences between familial and sporadic PanCa cases regarding the presence of diabetes and that diabetes was not a risk factor for pancreatic cancer $[23,24]$.

\section{Bilateral mechanism between PanCa and diabetes}

There has been a paradigm shift in the approach to understanding the relationship between PanCa and diabetes, as research has progressed into identifying the potential mechanisms that diabetes drive PanCa (Table 1).

\section{Pancreatic duct enlargement and hypertension}

Pancreatic duct enlargement and hypertension are more common in PanCa patients with diabetes than those without. Furthermore, mechanical obstruction of the pancreatic duct may be involved in the pathophysiology of diabetes in patients with PanCa [25]. Of note, using a high-fat diet-fed rat model of type 2 diabetes, Butler et al. noted that exocrine duct replication is increased tenfold by obesity and fourfold by diabetes, which is a predisposing factor for pancreatitis and PanCa [26].

\section{Hyperinsulinemia and insulin resistance}

Diabetes is usually characterized by profound peripheral insulin resistance in PanCa patients. Schneider et al. found that although half of the hamsters in their highfat group developed malignant lesions with increased hyperplasia, the premalignant lesions were found within the islets. This finding may explain why the association between PanCa and obesity is usually associated with peripheral insulin resistance [27].

The intracellular mechanism of insulin resistance in PanCa has been investigated. Liu et al. found multiple defects in glycogen synthesis in PanCa patients with or without diabetes. Furthermore, the fractional velocity of glycogen synthase was decreased, whereas glycogen phosphorylase $\mathrm{a}$ and $\mathrm{b}$ activities were increased, in diabetic PanCa patients. However, glycogen phosphorylase mRNA levels were not significantly different, meaning that the insulin resistance associated with PanCa is associated with 
Table 1 The potential mechanisms of diabetes in PanCa

\begin{tabular}{llll}
\hline Parameters & & Role in PanCa & Refs \\
\hline Pancreatic duct & Enlargement & Mechanical obstruction & [24] \\
& Replication increased & Predisposing factor & [25] \\
Hyperinsulinism and insulin resistance & Post-insulin receptor defect & Impaired glycogen synthesis and storage & [27] \\
& Plasma glucagon levels and IAPP & Early development of PanCa & [28] \\
Tumor size & Polymorphism of -23Hphl (A/T) & Pathogenesis of PanCa & Decreased postresection survival \\
Genetic variants & Increased & Enhanced growth & [31] \\
& & Increased risk & [33] \\
\hline
\end{tabular}

$I A P P$, islet amyloid polypeptide; PanCa, pancreatic cancer.

a post-insulin receptor defect, which impairs skeletal muscle glycogen synthesis and glycogen storage, leading to the hyperglycemia commonly observed in relation to PanCa [28]. While investigating islet function and secretion during early development of PanCa, Permert et al. found that plasma glucagon and islet amyloid polypeptide (IAPP) were significantly increased at 12 and 27 weeks, respectively, showing that islet hormone changes accompany the early development of pancreatic tumors in the hamster pancreatic cancer model [29]. Krechler et al. have studied the associations of the single nucleotide polymorphism -23HphI, which neighbors the variable number of tandem repeats locus in the upstream promoter of the insulin gene (INS), with PanCa and type 2 diabetes, and found that polymorphism of $-23 \mathrm{HphI}(\mathrm{A} / \mathrm{T})$ may play a role in the pathogenesis of $\mathrm{PanCa}$ and could contribute to tumor staging [30].

\section{Tumor size increased by diabetes}

Tumor size is an important prognostic factor for PanCa, as patients with small tumors have better prognosis and survival after surgery than those with large tumors [31]. $\mathrm{Chu}$ et al. examined the records of resected PanCa patients and found that preexisting diabetes is associated with reduced survival in patients undergoing resection for PanCa. Additionally, PanCa with new-onset diabetes may exhibit increased tumor size and decreased postresection survival [32]. When hamster $\mathrm{H} 2 \mathrm{~T}$ pancreatic carcinoma cells were implanted into the cheek pouches of Syrian hamsters, tumor size, tumor weight, and total tumor DNA content were significantly greater in animals with diabetes, which shows that diabetes appears to promote the growth of PanCa cells in the hamster [33].

\section{Genotype and the progression of PanCa in diabetes}

Dong et al. hypothesized that genetic variants in glucose metabolism modify individual susceptibility to PanCa, especially those associated with diabetes, and retrospectively genotyped 26 single-nucleotide polymorphisms in five glucose metabolism genes. The $H K 2$ R844K GA/AA genotype was associated with a reduced risk of PanCa among nondiabetic individuals but with increased risk among diabetic patients. Their findings show a potential role of the HK2 gene, alone or in combination with diabetes, in modifying the risk of PanCa [34]. In a case-control study, Fryzek et al. found that diabetes diagnosed five or more years prior was associated with pancreatic cancer that was positive for K-ras codon 12 mutations, but not meaningfully related to patients with p53 mutations, though further large-scale studies are warranted [35].

Subsequent studies have identified a multitude of molecules, for which expression was altered in cancer cells, thus suggesting a potential role for these molecules in PanCa (Table 2).

Insulin-like growth factor 1 (IGF-1) and IGF-1 receptor are highly expressed in pancreatic cancer cells [36]. Suzuki et al. showed that polymorphic variants of the IGF genes alone or in concert with diabetes increase the risk of PanCa [37]. Thus, individual genetic variations in the IGF axis may predict worse survival in patients with PanCa [38]. Basso et al. isolated a 14-amino-acid peptide from S100A8 in PanCa tissue from diabetics and found that NT-S100A8 exerts a mild effect on PanCa cell growth in BxPC3, while it reduces PanCa cell invasion in MiaPaCa2 and Panc1, possibly by activating Akt and NF-kB signaling $[39,40]$. Furthermore, Zhou et al. found that the regenerating gene (REG) I-alpha protein was preferentially expressed in cancerous tissues and cancer cells of PanCa patients with diabetes and that overexpression of this protein resulted in accelerated cell proliferation and consequently tumor growth, both in vitro and in vivo [41]. A systemic inflammatory response is often observed in PanCa. For example, C-reactive protein was an independent predictor of survival [42]. Furthermore, circulating levels of several cytokines were high in patients with pancreatic carcinoma. Interleukin 6 , which is released in large amounts by the inflamed pancreas in PanCa, may contribute to diabetes [43]. 
Table 2 Molecular factors involved in progression in PanCa cells related to diabetes

\begin{tabular}{llll}
\hline Molecules & Expression levels & Role in PanCa & Refs \\
\hline IGF-1 and receptor & Increased & Increase the risk and worse survival & [35,36] \\
14-amino-acid peptide from S100A8 & Increased & Promote the growth of PanCa by activating Akt and NF-KB signaling & [38,39] \\
Regenerating gene I alpha protein & Increased & Accelerated cell proliferation & [40] \\
& Increased & Predictors of poor survival \\
& Increased & Contribute to determining diabetes \\
\hline
\end{tabular}

IGF-1, insulin-like growth factor 1; PanCa, pancreatic cancer.

The association between diabetes and PanCa has long been recognized as that long-standing diabetes is thought to be an etiologic factor for PanCa and new-onset diabetes mellitus may be a manifestation of the cancer, both of which are characterized by hyperglycemia. The potential mechanisms of hyperglycemia in PanCa are shown in Table 3.

In a microarray analysis of myoblasts cultured in $\mathrm{PanCa}$ cell-conditioned media, Basso et al. found that lactate production and induced proteolysis were enhanced in the myoblasts, which can induce hyperglycemia [44]. Hyperglycemia and oxidative stress can lead to the accumulation of advanced glycation end products (AGEs). Studies have reported the strong expression of RAGE in MiaPaCa-2 and Panc- 1 that have high metastatic ability $[45,46]$. Reactive oxygen species (ROS) appear to be linked to PanCa. ROS have also been suggested to be mitogenic and capable of stimulating cell proliferation. In diabetic individuals, hyperglycemia in susceptible cells results in the overproduction of superoxide by the mitochondrial electron transport chain, and this process is the key to initiating all damaging pathways related to diabetes [47]. Hyperglycemia also specifically activates polyol metabolism with a consequent decrease in $\mathrm{Na}+, \mathrm{K}+-$ ATPase activity in pancreatic duct epithelial cells [48]. Moreover, hyperglycemia enhances the invasive and migratory activity of pancreatic cancer cells via hydrogen peroxide and the increased expression of urokinase plasminogen activator (uPA) [49].

Hyperglycemia can attenuate antioxidant enzyme activity and in turn create a state of oxidative stress [50]. The PanCa lines BxPC-3, MiaPaCa-2, and AsPC-1 have decreased manganese superoxide dismutase (MnSOD) immunoreactive protein expression and activity, and decreases in MnSOD correlate well with increased rates of tumor cell proliferation as determined by cell doubling time [51]. Cullen et al. found that the cytoplasmic values of MnSOD, catalase, and glutathione peroxidase were decreased in pancreatic cells from chronic pancreatitis specimens when compared with normal pancreas [52]. Additionally, elevated fructose may directly contribute to oxidative stress in pancreatic cancer. Suzuki et al. showed that fructose increases $\mathrm{H} 2 \mathrm{O} 2$ levels and lipid peroxidation of hamster islet tumor cells, which originated from hamster pancreatic beta cells. Furthermore, glutathione peroxidase $(\mathrm{GPx})$ is inactivated by fructose, and the mRNA expression of GPx is suppressed by fructose [53].

Glial cell line-derived neurotrophic factor (GDNF) is a chemoattractant for pancreatic cancer cells in the processes of tumor progression, migration and invasion. In in vitro studies, Jemal et al. have confirmed the stimulating effect of GDNF on the proliferation and invasion of

Table 3 The potential mechanisms of hyperglycemia in PanCa progression

\begin{tabular}{|c|c|c|c|c|}
\hline Parameters & & Expression levels & Role in PanCa & Refs \\
\hline RAGE & & Increased & Increased metastatic ability & {$[44,45]$} \\
\hline \multirow[t]{2}{*}{ ROS } & Hydrogen peroxide & Increased & Enhanced the invasive and & {$[46,48]$} \\
\hline & & Increased & migratory activity & \\
\hline Antioxidant & $\mathrm{MnSOD}$ & Decreased & Enhanced the invasive and migratory activity & {$[50,51]$} \\
\hline \multirow[t]{2}{*}{ enzymes } & Catalase, glutathione peroxidase & Decreased & & \\
\hline & & Decreased & & \\
\hline \multirow[t]{5}{*}{ Cytokines and their receptors } & GDNF and RET & Increased & Enhanced cell proliferation & [55] \\
\hline & EGF & Increased & Enhanced cell proliferation & {$[56]$} \\
\hline & EGFR & Transactivation & Enhanced cell proliferation & \\
\hline & NGF & Increased & Aggravated the process of perineural invasion & [58] \\
\hline & P75 & Decreased & & \\
\hline
\end{tabular}

$E G F$, epidermal growth factor; EGFR, epidermal growth factor receptor; GDNF, glial cell line-derived neurotrophic factor; $M n S O D$, manganese superoxide dismutase; $N G F$, nerve growth factor; PanCa, pancreatic cancer; RAGE, receptor for advanced glycation end products; ROS, reactive oxygen species; $u P A$, urokinase plasminogen activator. 
pancreatic cancer cells through the activation of the RET tyrosine kinase receptor [54,55]. Glucose alters the expression of GDNF and RET in a concentrationdependent manner, corresponding with the alterations in cell proliferation. Upregulation of the GDNF and RET ligand-receptor interaction might participate in the glucose-induced cancer progression [56]. High glucose also promotes PanCa cell proliferation via the induction of epidermal growth factor (EGF) expression and transactivation of EGFR [57].

The role of hyperglycemia in perineural invasion in pancreatic cancer is not clear. We have hypothesized that hyperglycemia promotes perineural invasion in PanCa by effects on nerve and cancer cells, respectively [58]. Our clinical study also showed that nerve damage and regeneration occur simultaneously in the tumor microenvironment of PanCa patients with hyperglycemia, thereby aggravating the process of perineural invasion. The abnormal expression of nerve growth factor (NGF) and p75 may also be involved in this process and subsequently lead to a lower rate of curative surgery [59].

\section{Diabetes and the early diagnosis of PanCa}

Recently, there has emerged a growing understanding that new-onset diabetes type 2, which begins up to 24 months before cancer diagnosis, can be an early manifestation of asymptomatic PanCa [60]. The prevalence of diabetes is higher (40\%) and more frequently of the new-onset type in PanCa than in control groups [61]. It has been suggested that screening for PanCa should be performed in patients with new-onset hyperglycemia and diabetes [62]. Because new-onset diabetes occurs 50 to 100 times more commonly than pancreatic cancer, screening efforts to detect occult pancreatic cancer in patients with new-onset diabetes require a feasible method to detect type 3 diabetes as the cause of impaired glucose tolerance [7]. Although the diabetes observed in patients with PanCa seems similar to type 2 diabetes in impaired glucose tolerance and insulin resistance, it affects only $1 \%$ to $5 \%$ of all diabetic patients [63]. Further support for the concept that the growing pancreatic tumor produces substances that alter glucose metabolism comes from experimental studies of glucose utilization and lactate formation in mouse myoblasts [44].

\section{Clinical manifestation of PanCa-associated diabetes}

PanCa-associated diabetes has some specific characters in the clinic, which may be helpful for differentiation of PanCa-associated diabetes from type 2 diabetes (Table 4). Type 2 diabetes is common in the elderly and pancreatic cancer populations. In elderly subjects within two years of meeting criteria for diabetes, who have relatively low premorbid body mass index, experience weight loss, and have no family history of diabetes, a suspicion of pancreatic
Table 4 The potential differentiation between PanCaassociated diabetes and type 2diabetes in the clinic

\begin{tabular}{llll}
\hline Parameters & $\begin{array}{l}\text { PanCa-related } \\
\text { diabetes }\end{array}$ & $\begin{array}{l}\text { Type 2 } \\
\text { diabetes }\end{array}$ & Refs \\
\hline Age of onset & Aged 45-65 years & All ages & {$[66]$} \\
Body mass index & Relatively low & High & {$[63]$} \\
Family history of diabetes & No & Often & {$[63]$} \\
Body weight & Often loss & Often gain & {$[65]$} \\
Tumor stage and site & Similar & Similar & {$[67]$} \\
\hline
\end{tabular}

cancer is justified [64]. Impaired glucose tolerance or diabetes is often the first sign of PanCa and occurs shortly before other clinical symptoms occur, such as weight loss, malaise and pain [65]. Hart et al. compared body weight and fasting blood glucose at diabetes onset, one to two years before and at index date, and found that weight loss frequently precedes onset of PanCa-related diabetes, whereas new-onset primary type 2 diabetes is typically associated with weight gain, which may be an important clue to understanding the pathogenesis of PanCa-related diabetes [66]. Middle-aged diabetic men and women aged 45 to 65 years reportedly have the greatest risk of malignant neoplasms of the pancreas [67]. The prevalence of diabetes in PanCa did not differ by tumor stage or site. Median survival was similar in PanCa with and without diabetes [68]. Lin et al. found that PanCa should be considered in the list of precipitants for diabetic ketoacidosis in type 2 diabetes [69].

\section{Serological biomarkers}

Biomarkers may be a useful strategy for the early diagnosis of PanCa, which can differentiate PanCa-associated diabetes from the more common type 2 diabetes and have differential expression the various stages in PanCa (Table 5).

Perhaps the strongest evidence for the tumor itself as a source for diabetogenic factor(s) is derived from the observation that glucose metabolism is improved after resection of the PanCa [70]. The hypothesis that a tumor-associated factor elicits the development of diabetes in PanCa is also supported by the fact that the onset of diabetes predates the first symptoms of PanCa by as much as two years, that is, well before the tumor is large enough to induce degradation of pancreatic islets [71]. However, the use of a biomarker may help to differentiate, PanCa-associated diabetes from the more common type 2 diabetes [61]. IAPP causes hyperglycemia by inhibiting muscle glycogen synthesis and stimulating glucose release from the muscles [72]. Permert et al. found that plasma glucagon and IAPP were significantly increased at 12 and 27 weeks, respectively, demonstrating that islet hormone changes accompany the early development of pancreatic tumors in the hamster pancreatic model [29]. However, Saruc et al. 
Table 5 Biomarkers involved in PanCa cancer with diabetes

\begin{tabular}{|c|c|c|c|c|}
\hline Biomarkers & Site & Expression levels & Role & Refs \\
\hline \multirow[t]{2}{*}{ IAPP } & Serum & Increased & Early stage of PanCa & {$[28]$} \\
\hline & Tissue & Decreased & Early stage of PanCa & {$[72,73]$} \\
\hline Glucagon/insulin ratio & Serum & Increased & Identify PanCa in patients with new-onset DM & [74] \\
\hline Adrenomedullin & Serum & Increased & Potential biomarker of PanCa-related DM & [75] \\
\hline Fatty acid binding protein-1 & Tissue & Increased & Diagnosis of PanCa & [76] \\
\hline A 14-amino-acid peptide from S100A8 & Serum & Increased & Identify PanCa in patients with new-onset DM & [38] \\
\hline Vanin-1 and matrix metalloproteinase 9 & Serum & Increased & Potential biomarker of PanCa-related DM & [77] \\
\hline Higher CA 19-9 and/or CEA & Serum & Increased & Screen early PanCa & [79] \\
\hline Erc/Mesothelin & Serum & Increased & Screen early PanCa & [81] \\
\hline
\end{tabular}

$C A$, cancer antigen; $C E A$, carcinoembryonic antigen; $D M$, diabetes mellitus; IAPP, islet amyloid polypeptide; $P a n C a$, pancreatic cancer.

compared the IAPP-expressing cells between cancer area and tumor-free area, and found a decrease rather than an increase in the number of IAPP-expressing cells in PanCa. The development of diabetes in subjects prone to pancreatic cancer could be a red flag for malignancy [73]. Katsumichi et al. also found that the number of IAPPexpressing cells was significantly lower in diabetes and in the tumor area but not in the tumor-free region [74].

Kolb et al. found significant differences in the serum glucagon/insulin ratio in patients with PanCa-associated diabetes and type 2 diabetes, with a borderline cut-off of 7.4 ng/mU glucagon/insulin [75]. Aggarwal et al. found that adrenomedullin (AM) is overexpressed in PanCa tissue and plasma, especially in association with diabetes. Additionally, plasma AM is elevated in PanCa. Further studies in a larger cohort of patients are planned to validate $\mathrm{AM}$ as a potential biomarker of PanCa-associated diabetes [76]. Using a novel translational bioinformatics approach, Sharaf et al. identified fatty acid binding protein-1 (FABP-1) as having a significant positive association with PanCa on tissue microarrays, which was further strengthened by the presence of diabetes [77]. Using microarray analysis and RT-PCR, Huang et al. demonstrated that the combination of vanin-1 and matrix metalloproteinase 9 may be used as a novel blood biomarker panel for the discrimination of pancreatic cancer-associated diabetes from type 2 diabetes [78]. In addition, Basso et al. isolated a 14-amino-acid peptide from S100A8 in PanCa tissue from PanCa patients with diabetes. As S100A8 impairs the catabolism of glucose by myoblasts in vitro and may cause hyperglycemia in vivo, it might be helpful in diagnosing PanCa in patients with recent-onset diabetes mellitus [39]. Selective stimulation of amylin secretion was demonstrated when isolated pancreatic islet cells were incubated in media conditioned with Panc-1 as compared to unconditioned media [79]. Cancer antigen (CA) 19-9 is used in the diagnosis of pancreatic cancer but is also a marker of pancreatic tissue damage that might be caused by diabetes. Thus, the diagnosis of new-onset diabetes combined with higher CA 19-9 and/or carcinoembryonic antigen (CEA) might be regarded as a useful tool to screen early pancreatic cancer [80].

Amadori-glycated phosphatidylethanolamine (Amadori$\mathrm{PE})$, known as a reliable indicator of lipid glycation in vivo, is a nonenzymatically glycated lipid formed under hyperglycemic conditions. Using the streptozotocin (STZ)induced diabetic rat model, Sookwong et al. found high levels of Amadori-PE in the blood and in organs that are strongly affected by diabetes, such as the kidney with a significant increase in STZ rats seven days after STZ treatment, suggesting that Amadori-PE may be a useful predictive marker for early-stage diabetes [81]. Diabetes mellitus could be a risk factor for PanCa. Eitsuka et al. found that Amadori-PE-enhanced cellular telomerase, which contributed to the infinite replicative potential of Panc-1 cancer cells in a time- and dose-dependent manner by upregulating human telomerase reverse transcriptase (hTERT) expression through induction of c-myc. These results provide experimental evidence for a novel role of Amadori-PE in linking diabetes and PanCa [82].

Navaglia et al. introduced the technique of surfaceenhanced laser desorption and ionization time-of-flight mass spectrometry, which permits identification of new peptides that, in addition to CA 19-9, enable the correct classification of the vast majority of patients with pancreatic cancer, who can be distinguished from patients with chronic pancreatitis or type 2 diabetes mellitus [83]. To identify biomarkers for early PanCa, Fukamachi et al. established transgenic rats carrying a mutated $\mathrm{H}$-ras or $\mathrm{K}$-ras gene as a PanCa model, and found that even in rats with very small microscopic ductal carcinoma lesions, elevated serum Erc/Mesothelin can be detected [84].

\section{Diabetes and the treatment for PanCa}

Pelaez-Luna et al. determined the resectability of PanCa on abdominal computed tomography (CT) scans performed prior to clinical diagnosis and correlated resectability with 
onset of diabetes. They found that PanCa is frequently undetectable or resectable on CT scans performed $\geq 6$ months prior to clinical diagnosis. At onset of diabetes, pancreatic cancers are generally resectable [85]. Several studies have reported the risk of antidiabetic drugs on cancer incidence. Chang et al. examined cancer incidence associated with use of insulin glargine, and found usage was positively associated with pancreatic and prostate cancers in men [86]. To elucidate the effect of pharmacotherapy for diabetes in cancer patients, Feng et al. found that insulin and glucose promoted cancer cell proliferation and contributed to chemoresistance, with metformin and rosiglitazone suppressing cancer cell growth and inducing apoptosis of four human cancer cell lines in vitro. Both drugs affected signaling in the protein kinase B (AKT)/ mammalian target of rapamycin pathway, which provides experimental evidence to support further investigation of metformin and rosiglitazone as first-line therapies for type 2 diabetes in cancer patients [87]. Univariate and multivariate analyses were performed to determine whether the medications were predictive of early mortality in patients undergoing resection for PanCa.

Chagpar et al. found that patients with PanCa being treated for pre-existing diabetes with insulin therapy have an increased risk of early postoperative mortality [88]. To explore the ability of metformin to protect against cancer risk in Orientals, the possible metformin effect on total, esophageal, gastric, colorectal, hepatocellular and pancreatic cancers was examined in a Taiwanese cohort. In diabetics not taking anti-hyperglycemic medication, cancer incidence density increased at least twofold in total, including pancreatic cancers. The metformin dosage needed to observe a significant decrease in cancer incidence was $\leq 500 \mathrm{mg} /$ day [89].

In addition to its ability to reduce insulin resistance, the antidiabetic drug, metformin has shown antitumor properties and is increasingly being considered as a drug for the prevention and treatment of obesity-related cancers [90]. Currie et al. reported that the effect of metformin might be tumor-specific, in that its use was associated with a reduced risk of cancer of the colon and pancreas, but not of cancer of the breast or prostate [91]. The antitumor effect of metformin seems to be mediated via its ability to increase the AMP-activated protein kinase (AMPK) signaling pathway [92]. Metformin negatively regulates mammalian target of rapamycin (mTOR) complex 1 (mTORC1) and the crosstalk between insulin/IGF-1 receptor and G-protein coupled receptor (GPCR) signaling, thus inhabiting the development of certain types of cancer [93].

Treatment with metformin induced striking and sustained increase in the phosphorylation of AMPK at Thr (172), and a selective AMPK inhibitor (compound C, at $5 \mu \mathrm{mol} / \mathrm{L})$ reversed the effects of metformin on $(\mathrm{Ca}(2+))(\mathrm{i})$ and DNA synthesis, indicating that metformin acts through AMPK activation [94].

Using Cox proportional hazards models and controlling for smoking and alcohol use, a ten-year prospective cohort study reported that the stratum with the highest fasting serum glucose had higher death rates from all cancers combined compared with the stratum with the lowest level. By cancer site, the association was strongest for pancreatic cancer when comparing the highest and lowest strata in men and in women in Korea [95].

\section{Conclusions}

Diabetes is widely considered to be associated with PanCa. Epidemiological studies have confirmed a higher incidence of diabetes in PanCa, while a higher incidence of PanCa in diabetes was also confirmed. These associations provide evidence-based medical support for further studies examining the mechanism of interaction.

Diabetes may directly promote the progression of PanCa by pancreatic duct enlargement and hypertension, as well as increased tumor size. Hyperinsulinemia and insulin resistance, cytokines, hyperglycemia and genotype change are also important factors involved in the mechanism of occurrence, proliferation, invasion, metastasis and prognosis of PanCa with diabetes. Up to $80 \%$ of PanCa patients are either hyperglycemic or diabetic, both of which can be detected in the presymptomatic phase. Hyperglycemia and glucose tolerance abnormalities may be the first clinical manifestation of diabetes, which can also be tested by a health examination. If the danger signal of hyperglycemia and glucose tolerance abnormalities can be emphasized, some of the hazard population of PanCa may be screened. Novel biomarkers of early PanCa are also being studied. The combination of defining a hazard population of PanCa and the use of novel biomarkers discriminating common type 2 diabetes from PanCa-associated diabetes should be the next direction in the early diagnosis of PanCa.

Antidiabetic drugs have different effects on the occurrence and prognosis of PanCa. Metformin can lower the risk of PanCa, the mechanism of which has also been explored, whereas insulin use exerts a converse effect. The novel usage of metformin for its antitumor effect and its potential mechanism may be another direction to improve the prognosis of PanCa.

\section{Abbreviations}

AM: Adrenomedullin; Amadori-PE: Amadori-glycated

phosphatidylethanolamine; AMPK: AMP-activated protein kinase; DM: Diabetes mellitus; EGF: Epidermal growth factor; EGFR: Epidermal growth factor receptor; GDNF: Glial cell line-derived neurotrophic factor; GPx: Glutathione peroxidase; hTERT: Human telomerase reverse transcriptase; IAPP: Islet amyloid polypeptide; IGF-1: Insulin-like growth factor 1; MnSOD: Manganese superoxide dismutase; mTOR(1): Mammalian target of rapamycin (complex 1); NGF: Nerve growth factor; PanCa: Pancreatic cancer; (R)AGE: (receptor for) advanced glycation end products; ROS: Reactive oxygen species; uPA: Urokinase plasminogen activator. 


\section{Competing interest}

The authors declare they have no competing of interest.

\section{Authors' contributions}

JHL, HL and WL wrote the manuscript, and GC, QYM and LH approved it. All authors read and approved the final manuscript.

\section{Acknowledgment}

This study was supported by the National Natural Scientific Foundation of China (2009, grant number 30900705), a Scientific Grant from Xi'an City (2009, number GG06718), and a 13115 major project of Shaanxi province (number 2010ZDKG-49) and a Scientific Foundation of the Second Affiliated Hospital Medical College, Xi'an Jiaotong University (RC (XM) 201107).

\section{Author details}

${ }^{1}$ Department of General Surgery, Second Affiliated Hospital, School of Medicine, Xi'an Jiaotong University, 157 West 5th Road, Xi'an 710004, People's Republic of China. ${ }^{2}$ Department of Hepatobiliary Surgery, First Affiliated Hospital, Medical College, Xi'an Jiaotong University, 277 Yanta West Road, Xi'an 710061, People's Republic of China.

Received: 20 April 2012 Accepted: 11 August 2012

Published: 24 August 2012

\section{References}

1. Hidalgo M: Pancreatic cancer. N Engl J Med 2010, 362:1605-1617.

2. Eheman C, Henley SJ, Ballard-Barbash R, Jacobs EJ, Schymura MJ, Noone AM, Pan L, Anderson RN, Fulton JE, Kohler BA, Jemal A, Ward E, Plescia M, Ries LA, Edwards BK: Annual Report to the Nation on the status of cancer, 1975-2008, featuring cancers associated with excess weight and lack of sufficient physical activity. Cancer 2012, 118:2338-2366.

3. Grote VA, Becker S, Kaaks R: Diabetes mellitus type 2 - an independent risk factor for cancer? Exp Clin Endocrinol Diabetes 2010, 118:4-8.

4. Huxley R, Ansary-Moghaddam A, Berrington De-González A, Barzi F, Woodward M: Type-II diabetes and pancreatic cancer: a meta-analysis of 36 studies. Br J Cancer 2005, 92:2076-2083.

5. Li D, Tang H, Hassan MM, Holly EA, Bracci PM, Silverman DT: Diabetes and risk of pancreatic cancer: a pooled analysis of three large case-control studies. Cancer Causes Control 2011, 22:189-197.

6. Ogunleye AA, Ogston SA, Morris AD, Evans JM: A cohort study of the risk of cancer associated with type 2 diabetes. Br J Cancer 2009, 101:1199-1201.

7. Magruder JT, Elahi D, Andersen DK: Diabetes and pancreatic cancer: chicken or egg? Pancreas 2011, 40:339-351.

8. Johnson JA, Bowker SL, Richardson K, Marra CA: Time-varying incidence of cancer after the onset of type 2 diabetes: evidence of potential detection bias. Diabetologia 2011, 54:2263-2271.

9. Perrin MC, Terry MB, Kleinhaus K, Deutsch L, Yanetz R, Tiram E, Calderon R, Friedlander $Y$, Paltiel O, Harlap S: Gestational diabetes as a risk factor for pancreatic cancer: a prospective cohort study. BMC Med 2007, 5:25-31

10. Tseng $\mathrm{CH}$ : New-onset diabetes with a history of dyslipidemia predicts pancreatic cancer. Pancreas 2012, Jun. [Epub ahead of print].

11. Ogawa Y, Tanaka M, Inoue K, Yamaguchi K, Chijiiwa K, Mizumoto K, Tsutsu N, Nakamura Y: A prospective pancreatographic study of the prevalence of pancreatic carcinoma in patients with diabetes mellitus. Cancer 2002, 94:2344-2349.

12. Hong SG, Jung SJ, Joo MK, Lee BJ, Yeon JE, Park JJ, Byun KS, Bak YT: Prevalence of pancreatic cancer in diabetics and clinical characteristics of diabetes-associated with pancreatic cancer-comparison between diabetes with and without pancreatic cancer. Korean J Gastroenterol 2009, 54:167-173

13. Chari ST, Leibson CL, Rabe KG, Ransom J, de Andrade M, Petersen GM: Probability of pancreatic cancer following diabetes: a population-based study. Gastroenterology 2005, 129:504-511.

14. Jamal MM, Yoon EJ, Vega KJ, Hashemzadeh M, Chang KJ: Diabetes mellitus as a risk factor for gastrointestinal cancer among American veterans. World J Gastroenterol 2009, 15:5274-5278.

15. Stevens RJ, Roddam AW, Beral V: Pancreatic cancer in type 1 and youngonset diabetes: systematic review and meta-analysis. Br J Cancer 2007, 96:507-509.
16. Saruç M, Karaarslan M, Rasa K, Saygili O, Ince U, Baysal C, Pour PM, Cakmakçi $M$, Tözün N: Pancreatic cancer and glucose metabolism. Turk J Gastroenterol 2009, 20:257-260.

17. Wang F, Herrington M, Larsson J, Permert J: The relationship between diabetes and pancreatic cancer. Mol Cancer 2003, 2:4.

18. Wang F, Gupta S, Holly EA: Diabetes mellitus and pancreatic cancer in a population-based case-control study in the San Francisco Bay Area, California. Cancer Epidemiol Biomarkers Prev 2006, 15:1458-1463.

19. Aggarwal G, Rabe KG, Petersen GM, Chari ST: New-onset diabetes in pancreatic cancer: a study in the primary care setting. Pancreatology 2012, 12:156-161.

20. Permert J, Adrian TE, Jacobsson $P$, Jorfelt $L$, Fruin $A B$, Larsson J: Is profound peripheral insulin resistance in patients with $\mathrm{PaC}$ caused by a tumorassociated factor? Am J Surg 1993, 165:61-67.

21. Kuang TT, da Jin Y, Wang DS, Xu XF, Ni XL, Wu WC, Lou WH: Clinical epidemiological analysis of the relationship between pancreatic cancer and diabetes mellitus: data from a single institution in China. J Dig Dis 2009, 10:26-29.

22. Matsubayashi H, Maeda A, Kanemoto H, Uesaka K, Yamazaki K, Hironaka S, Miyagi $Y$, Ikehara $H$, Ono H, Klein A, Goggins M: Risk factors of familial pancreatic cancer in Japan: current smoking and recent onset of diabetes. Pancreas 2011, 40:974-978.

23. Bartsch DK, Kress R, Sina-Frey M, Grutzmann R, Gerdes B, Pilarsky C, Heise JW, Schulte KM, Colombo-Benkmann M, Schleicher C, Witzigmann H, Pridohl O, Ghadimi M, Horstmann OV, Berndorff W, Jochimsen L, Schmidt J, Eisold S, Estevez-Schwarz L, Hahn SA, Schulmann K, Bock W, Gress T, Zugel N, Breitschaft K, Prenzel K, Messmann H, Endlicher E, Schneider M, Ziegler A, et al: Prevalence of familial pancreatic cancer in Germany. Int J Cancer 2004, 110:902-906.

24. Rulyak SJ, Lowenfels AB, Maisonneuve P, Brentnall TA: Risk factors for the development of pancreatic cancer in familial pancreatic cancer kindreds. Gastroenterology 2003, 124:1292-1299.

25. Uni W, Shelly N, Richard Z: Pancreatic adenocarcinoma (PA) and diabetes mellitus (DM). Gastroenterology 2010, 138:S-553.

26. Butler AE, Galasso R, Matveyenko A, Rizza RA, Dry S, Butler PC: Pancreatic duct replication is increased with obesity and type 2 diabetes in humans. Diabetologia 2010, 53:21-26.

27. Schneider MB, Matsuzaki H, Haorah J, Ulrich A, Standop J, Ding XZ, Adrian TE, Pour PM: Prevention of $\mathrm{PaC}$ induction in hamsters by metformin. Gastroenterology 2001, 120:1263-1270.

28. Liu J, Knezetic JA, Strömmer L, Permert J, Larsson J, Adrian TE: The intracellular mechanism of insulin resistance in pancreatic cancer patients. J Clin End Met 2000, 85:1232-1238.

29. Permert J, Herrington M, Kazakoff K, Pour PM, Adrian TE: Early changes in islet hormone secretion in the hamster pancreatic cancer model. Teratog Carcinog Mutagen 2001, 21:59-67.

30. Krechler T, Jachymova M, Pavlikova M, Vecka M, Zeman M, Krska Z, Svestka T, Zak A: Polymorphism -23HPhl in the promoter of insulin gene and pancreatic cancer: a pilot study. Neoplasma 2009, 56:26-32.

31. Pantalone D, Ragionieri I, Nesi G: Improved survival in small pancreatic cancer. Dig Surg 2001, 18:41-46.

32. Chu CK, Mazo AE, Goodman M, Egnatashvili V, Sarmiento JM, Staley CA, Galloway JR, Adsay NV, Jacobs S, Kooby DA: Preoperative diabetes mellitus and long-term survival after resection of pancreatic adenocarcinoma. Ann Surg Oncol 2010, 17:502-513.

33. Fisher WE, McCullough PJ, Ray MB, Rogers DH, Bell RH Jr: Diabetes enhances growth of pancreatic carcinoma cells. Surgery 1988, 104:431-436.

34. Dong X, Li Y, Chang P, Tang H, Hess KR, Abbruzzese JL, Li D: Glucose metabolism gene variants modulate the risk of pancreatic cancer. Cancer Prev Res (Phila) 2011, 4:758-766.

35. Fryzek JP, Garabrant DH, Schenk M, Kinnard M, Greenson JK, Sarkar FH: The association between selected risk factors for pancreatic cancer and the expression of p53 and K-ras codon 12 mutations. Int J Gastrointest Cancer 2006, 37:139-145.

36. Bergmann U, Funatomi H, Yokoyama M, Beger HG, Korc M: Insulin-like growth factor I overexpression in human pancreatic cancer: evidence for autocrine and paracrine roles. Cancer Res 1995, 55:2007-2011.

37. Suzuki H, Li Y, Dong X, Hassan MM, Abbruzzese JL, Li D: Effect of insulinlike growth factor gene polymorphisms alone or in interaction with diabetes on the risk of pancreatic cancer. Cancer Epidemiol Biomarkers Prev 2008, 17:3467-3473. 
38. Dong X, Javle M, Hess KR, Shroff R, Abbruzzese JL, Li D: Insulin-like growth factor axis gene polymorphisms and clinical outcomes in pancreatic cancer. Gastroenterology 2010, 139:464-473. 473.e1-3.

39. Basso D, Greco E, Fogar P, Pucci P, Flagiello A, Baldo G, Giunco S, Valerio A, Navaglia F, Zambon CF, Falda A, Pedrazzoli S, Plebani M: Pancreatic cancerderived S-100A8 N-terminal peptide: a diabetes cause? Clin Chim Acta 2006, 372:120-128

40. Basso D, Greco E, Padoan A, Fogar P, Scorzeto M, Fadi E, Bozzato D, Moz S, Navaglia F, Zambon CF, Seraglia R, De Carlo E, Valerio A, Reggiani C, Pedrazzoli S, Plebani M: Altered intracellular calcium fluxes in pancreatic cancer induced diabetes mellitus: relevance of the S100A8 N-terminal peptide (NT-S100A8). J Cell Physiol 2011, 226:456-468.

41. Zhou L, Zhang R, Wang L, Shen S, Okamoto $H$, Sugawara A, Xia L, Wang $X$ Noguchi N, Yoshikawa T, Uruno A, Yao W, Yuan Y: Upregulation of REG lalpha accelerates tumor progression in pancreatic cancer with diabetes. Int J Cancer 2010, 127:1795-1803.

42. Tingstedt $B$, Johansson P, Andersson B, Andersson R: Predictive factors in pancreatic ductal adenocarcinoma: role of the inflammatory response. Scand J Gastroenterol 2007, 42:754-759.

43. Fogar P, Basso D, Pasquali C, Piva MG, Brigato L, De Paoli M, Galeotti F, Corsini A, Plebani M: Portal but not peripheral serum levels of interleukin 6 could interfere with glucose metabolism in patients with pancreatic cancer. Clin Chim Acta 1998, 277:181-189.

44. Basso D, Millino C, Greco E, Romualdi C, Fogar P, Valerio A, Bellin M, Zambon CF, Navaglia F, Dussini N, Avogaro A, Pedrazzoli S, Lanfranchi G, Plebani M: Altered glucose metabolism and proteolysis in pancreatic cancer cell conditioned myoblasts: searching for a gene expression pattern with a microarray analysis of 5000 skeletal muscle genes. Gut 2004, 53:1159-1166.

45. Takada M, Koizumi T, Toyama H, Suzuki Y, Kuroda Y: Differential expression of RAGE in human pancreatic carcinoma cells. Hepatogastroenterology 2001, 48:1577-1578.

46. Takada M, Hirata K, Ajiki T, Suzuki Y, Kuroda Y: Expression of receptor for advanced glycation end products (RAGE) and MMP-9 in human pancreatic cancer cells. Hepatogastroenterology 2004, 51:928-930.

47. Brownlee M: Biochemistry and molecular cell biology of diabetic complications. Nature 2001, 414:813-820.

48. Busik JV, Hootman SR, Greenidge CA, Henry DN: Glucosespecific regulation of aldose reductase in capan-1 human pancreatic duct cells in vitro. $J$ Clin Invest 1997, 100:1685-1692.

49. Li W, Ma Q, Li J, Guo K, Liu H, Han L, Ma G: Hyperglycemia enhances the invasive and migratory activity of pancreatic cancer cells via hydrogen peroxide. Oncol Rep 2011, 25:1279-1287.

50. Sindhu RK, Koo JR, Roberts CK, Vaziri ND: Dysregulation of hepatic superoxide dismutase, catalase and glutathione peroxidase in diabetes: response to insulin and antioxidant therapies. Clin Exp Hypert 2004, 26:43-53.

51. Cullen JJ, Weydert C, Hinkhouse MM, Ritchie J, Domann FE, Spitz D, Oberley LW: The role of manganese superoxide dismutase in the growth of pancreatic adenocarcinoma. Cancer Res 2003, 63:1297-1303.

52. Cullen JJ, Mitros FA, Oberley LW: Expression of antioxidant enzymes in diseases of the human pancreas: another link between chronic pancreatitis and pancreatic cancer. Pancreas 2003, 26:23-27.

53. Suzuki K, Islam KN, Kaneto H, Ookawara T, Taniguchi N: The contribution of fructose and nitric oxide to oxidative stress in hamster islet tumor (HIT) cells through the inactivation of glutathione peroxidase. Electrophoresis 2000, 21:285-288.

54. Veit C, Genze F, Menke A, Hoeffert S, Gress TM, Gierschik P, Giehl K: Activation of phosphatidylinositol 3-kinase and extracellular signalregulated kinase is required for glial cell line-derived neurotrophic factor-induced migration and invasion of pancreatic carcinoma cells. Cancer Res 2004, 64:5291-5300.

55. Takahashi M: The GDNF/RET signaling pathway and human diseases. Cytokine Growth Factor Rev 2001, 12:361-373.

56. Liu H, Ma QY, Li JH: High glucose promotes cell proliferation and enhances GDNF and RET expression in pancreatic cancer cells. Mol Cell Biochem 2011, 347:95-101.

57. Han L, Ma Q, Li J, Liu H, Li W, Ma G, Xu Q, Zhou S, Wu E: High glucose promotes pancreatic cancer cell proliferation via the induction of EGF expression and transactivation of EGFR. PLoS One 2011, 6:e27074.
58. Li JH, Ma QY: Hyperglycemia promotes the perineural invasion in pancreatic cancer. Med Hypotheses 2008, 71:386-389.

59. Li J, Ma Q, Liu H, Guo K, Li F, Li W, Han L, Wang F, Wu E: Relationship between neural alteration and perineural invasion in pancreatic cancer patients with hyperglycemia. PLoS One 2011, 6:e17385.

60. Pannala R, Leibson CL, Rabe KG, Timmons LJ, Ransom J, de Andrade M, Petersen GM, Chari ST: Temporal association of changes in fasting blood glucose and body mass index with diagnosis of pancreatic cancer. Am $J$ Gastroenterol 2009, 104:2318-2325.

61. Chari ST, Leibson CL, Rabe KG, Timmons LJ, Ransom J, de Andrade M, Petersen GM: Pancreatic cancer-associated diabetes mellitus: prevalence and temporal association with diagnosis of cancer. Gastroenterology 2008, 134:95-101

62. Pannala R, Basu A, Petersen GM, Chari ST: New-onset diabetes: a potential clue to the early diagnosis of pancreatic cancer. Lancet Oncol 2009, 10:88-95.

63. Centers for Disease Control and Prevention: National Diabetes Fact Sheet. 2007.

64. Park HY, Song SY, Cho HC, Lee KH, Lee KT, Lee JK: Clinical characteristics of pancreatic cancer-associated new onset diabetes. Gastroenterology 2010, 138:1391.

65. Italian Pancreatic Cancer Study Group, Gullo L, Pezzilli R, Morselli-Labate AM: Diabetes and the risk of pancreatic cancer. N Engl J Med 1994, 331:81-84.

66. Hart PA, Kamada P, Rabe KG, Srinivasan S, Basu A, Aggarwal G, Chari ST: Weight loss precedes cancer-specific symptoms in pancreatic cancerassociated diabetes mellitus. Pancreas 2011, 40:768-772.

67. Chen HF, Chen P, Li CY: Risk of malignant neoplasm of the pancreas in relation to diabetes: a population-based study in Taiwan. Diabetes Care 2011, 34:1177-1179.

68. Pannala R, Leirness JB, Bamlet WR, Basu A, Petersen GM, Chari ST: Prevalence and clinical profile of pancreatic cancer-associated diabetes mellitus. Gastroenterology 2008, 134:981-987.

69. Lin MV, Bishop G, Benito-Herrero M: Diabetic ketoacidosis in type 2 diabetics: a novel presentation of pancreatic adenocarcinoma. J Gen Intern Med 2010, 25:369-373.

70. Permert J, Ihse I, Jorfeldt L, von Schenck H, Arnquist HJ, Larsson J: Improved glucose metabolism after subtotal pancreatectomy for pancreatic cancer. Br J Surg 1993, 80:1047-1050.

71. Chari ST, Zapiach M, Yadav D, Rizza RA: Beta-cell function and insulin resistance evaluated by HOMA in pancreatic cancer subjects with varying degrees of glucose intolerance. Pancreatology 2005, 5:229-233.

72. Leighton B, Cooper GJ: Pancreatic amylin and calcitonin gene-related peptide cause resistance to insulin in skeletal muscle in vitro. Nature 1988, 335:632-635.

73. Saruc M, Iki K, Pour PM: Morphometric studies in human pancreatic cancer argues against the etiological role of type 2 diabetes in pancreatic cancer. Histol Histopathol 2010, 25:423-432.

74. Katsumichi I, Pour PM: Diabetes mellitus in pancreatic cancer: is it a causal relationship? Am J Surg 2007, 194:S71-S75.

75. Kolb A, Rieder S, Born D, Giese NA, Giese T, Rudofsky G, Werner J, Büchler MW, Friess H, Esposito I, Kleeff J: Glucagon/insulin ratio as a potential biomarker for pancreatic cancer in patients with new-onset diabetes mellitus. Cancer Biol Ther 2009, 8:1527-1533.

76. Aggarwal G, Klee G, Fernandez-Zapico ME, Klee EW, Smyrk TC, Andrade M, Petersen GM, Chari ST: Adrenomedullin: a biomarker of pancreatic cancer-associated diabetes? Gastroenterology 2010, 138:S-551.

77. Sharaf RN, Butte AJ, Montgomery KD, Pai R, Dudley JT, Pasricha PJ: Computational prediction and experimental validation associating FABP1 and pancreatic adenocarcinoma with diabetes. BMC Gastroenterol 2011, 11:5.

78. Huang $H$, Dong $X$, Kang MX, Xu B, Chen Y, Zhang B, Chen J, Xie QP, Wu YL: Novel blood biomarkers of pancreatic cancer-associated diabetes mellitus identified by peripheral blood-based gene expression profiles. Am J Gastroenterol 2010, 105:1661-1669.

79. Ding X, Flatt PR, Permert J, Adrian TE: Pancreatic cancer cells selectively stimulate islet beta cells to secrete amylin. Gastroenterology 1998, 114:130-138.

80. Guo Q, Kang M, Zhang B, Chen Y, Dong X, Wu Y: Elevated levels of CA 19-9 and CEA in pancreatic cancer-associated diabetes. $J$ Cancer Res Clin Oncol 2010, 136:1627-1631. 
81. Sookwong P, Nakagawa K, Fujita I, Shoji N, Miyazawa T: Amadori-glycated phosphatidylethanolamine, a potential marker for hyperglycemia, in streptozotocin-induced diabetic rats. Lipids 2011, 46:943-952.

82. Eitsuka T, Nakagawa K, Ono Y, Tatewaki N, Nishida H, Kurata T, Shoji N, Miyazawa T: Amadori-glycated phosphatidylethanolamine up-regulates telomerase activity in PANC-1 human pancreatic carcinoma cells. FEBS Lett 2012, 586:2542-2547.

83. Navaglia F, Fogar P, Basso D, Greco E, Padoan A, Tonidandel L, Fadi E, Zambon CF, Bozzato D, Moz S, Seraglia R, Pedrazzoli S, Plebani M: Pancreatic cancer biomarkers discovery by surface-enhanced laser desorption and ionization time-of-flight mass spectrometry. Clin Chem Lab Med 2009, 47:713-723.

84. Fukamachi $\mathrm{K}$, Tanaka H, Hagiwara Y, Ohara H, Joh T, ligo M, Alexander DB, Xu J, Long N, Takigahira M, Yanagihara K, Hino O, Saito I, Tsuda H: An animal model of preclinical diagnosis of pancreatic ductal adenocarcinomas. Biochem Biophys Res Commun 2009, 390:636-641.

85. Pelaez-Luna M, Takahashi N, Fletcher JG, Chari ST: Resectability of presymptomatic pancreatic cancer and its relationship to onset of diabetes: a retrospective review of $\mathrm{CT}$ scans and fasting glucose values prior to diagnosis. Am J Gastroenterol 2007, 102:2157-2163.

86. Chang CH, Toh S, Lin JW, Chen ST, Kuo CW, Chuang LM, Lai MS: Associated with insulin glargine among adult type 2 diabetes patients - a nationwide cohort study. PLoS One 2011, 6:e21368.

87. Feng YH, Velazquez-Torres G, Gully C, Chen J, Lee MH, Yeung SC: The impact of type 2 diabetes and antidiabetic drugs on cancer cell growth. J Cell Mol Med 2011, 15:825-836.

88. Chagpar RB, Martin RC, Ahmad SA, Kim HJ, Rupp C, Weber S, Ebelhar A, Gilbert J, Brinkman A, Winslow E, Cho CS, Kooby D, Chu CK, Staley CA, McMasters KM, Scoggins CR: Medically managed hypercholesterolemia and insulin-dependent diabetes mellitus preoperatively predicts poor survival after surgery for pancreatic cancer. I Gastrointest Surg 2011, 15:551-557.

89. Lee MS, Hsu CC, Wahlqvist ML, Tsai HN, Chang YH, Huang YC: Type 2 diabetes increases and metformin reduces total, colorectal, liver and pancreatic cancer incidences in Taiwanese: a representative population prospective cohort study of 800,000 individuals. BMC Cancer 2011, 11:20

90. Becker S, Dossus L, Kaaks R: Obesity related hyperinsulinaemia and hyperglycaemia and cancer development. Arch Physiol Biochem 2009, 115:86-96.

91. Currie CJ, Poole CD, Gale EA: The influence of glucose-lowering therapies on cancer risk in type 2 diabetes. Diabetologia 2009, 52:1766-1777.

92. Zakikhani M, Dowling R, Fantus IG, Sonenberg N, Pollak M: Metformin is an AMP kinase-dependent growth inhibitor for breast cancer cells. Cancer Res 2006, 66:10269-10273.

93. Rozengurt E, Sinnett-Smith J, Kisfalvi K: Crosstalk between insulin/insulinlike growth factor-1 receptors and $\mathrm{G}$ protein-coupled receptor signaling systems: a novel target for the antidiabetic drug metformin in pancreatic cancer. Clin Cancer Res 2010, 16:2505-2511.

94. Kisfalvi K, Eibl G, Sinnett-Smith J, Rozengurt E: Metformin disrupts crosstalk between $\mathrm{G}$ protein-coupled receptor and insulin receptor signaling systems and inhibits pancreatic cancer growth. Cancer Res 2009, 69:6539-6545.

95. Nath SD, Habib SL, Abboud HE: Fasting serum glucose level and cancer risk in Korean men and women. JAMA 2005, 293:2210-2211.

\section{doi:10.1186/1477-7819-10-17}

Cite this article as: $\mathrm{Li}$ et al:: The bidirectional interation between pancreatic cancer and diabetes. World Journal of Surgical Oncology 2012 10:171

\section{Submit your next manuscript to BioMed Central and take full advantage of:}

- Convenient online submission

- Thorough peer review

- No space constraints or color figure charges

- Immediate publication on acceptance

- Inclusion in PubMed, CAS, Scopus and Google Scholar

- Research which is freely available for redistribution 